\title{
Cardiac Imaging for Risk Assessment of Malignant Ventricular Arrhythmias in Patients With Mitral Valve Prolapse
}

\author{
Bhupendar Tayal ${ }^{1,2}$, Francesca N. Delling ${ }^{3}$, Maan Malahfji ${ }^{1}$ and Dipan J. Shah ${ }^{1 *}$ \\ ' Division of Cardiovascular Imaging, Houston Methodist DeBakey Heart and Vascular Institute, Houston, TX, United States, \\ ${ }^{2}$ Department of Cardiolgy, Aalborg University Hospital, Aalborg, Denmark, ${ }^{3}$ Department of Cardiolgy, University of California, \\ San Francisco, San Francisco, CA, United States
}

\section{OPEN ACCESS}

Edited by:

Thomas A. Treibel,

University College London,

United Kingdom

Reviewed by:

Maria Aurora Morales,

National Research Council (CNR), Italy

Francesca Bursi,

University Hospital of Modena, Italy

Tomaz Podlesnikar,

Maribor University Medical

Centre, Slovenia

*Correspondence:

Dipan J. Shah

djshah@houstonmethodist.org

Specialty section:

This article was submitted to

Cardiovascular Imaging,

a section of the journal

Frontiers in Cardiovascular Medicine

Received: 19 June 2020 Accepted: 06 January 2021 Published: 15 February 2021

Citation:

Tayal B, Delling FN, Malahfii $M$ and Shah DJ (2021) Cardiac Imaging for

Risk Assessment of Malignant Ventricular Arrhythmias in Patients With Mitral Valve Prolapse.

Front. Cardiovasc. Med. 8:5744446.

doi: 10.3389/fcvm.2021.574446
Recent studies have described the occurrence of complex ventricular arrhythmias and sudden cardiac death among patients with mitral valve prolapse (MVP). The reported incidence rate of sudden cardiac death or ventricular tachycardia is about $1-1.5 \%$ among patients with MVP. Various imaging markers have been associated with this increased risk, including mitral annular disjunction, replacement fibrosis by late gadolinium enhancement, and mechanical dispersion. In this review, we briefly discuss how multimodality cardiac imaging can be applied to identify MVP patients with high risk of sudden cardiac death and complex ventricular arrhythmias.

Keywords: mitral valve prolapse, cardiac imaging, ventricular tachycardia, echocardiagraphy, cardiac magnet resonance imaging

\section{INTRODUCTION}

Mitral valve prolapse (MVP) has received renewed attention due to several studies documenting its association with scar substrate and increased risk of complex ventricular arrhythmias (VA) and sudden cardiac death (SCD) (1-3). Other important complications related to MVP are mitral regurgitation, infective endocarditis, cerebral embolic events, and heart failure (4). Historically, a mid-late systolic click was first described to be associated with mitral regurgitation by Barlow and Pocock (5). Later, Criley et al. demonstrated that this click associated with mitral regurgitation is due to mitral valve prolapse (6).

The current echocardiographic definition of MVP is displacement of one or both mitral leaflets in the left atrium below the annulus by at least $2 \mathrm{~mm}$ in the parasternal long-axis view (7). The prevalence of MVP in the general population is currently thought to be around 2-3\% $(8,9)$. However, historically, the reported prevalence of MVP has been described to be as high as 17$35 \%(10,11)$. These discrepancies are related to initial reports which defined MVP as the presence of $2 \mathrm{~mm}$ leaflet displacement in any apical echocardiographic view (two-, three-, or four-chamber). This led to an overdiagnosis of MVP primarily due to the assumption that the mitral valve is a planar structure, which was later refuted by the pioneering work of Levine et al. in the latter half of the 1980s $(7,12)$. Most of the MVP cases are sporadic in nature; however, studies have also demonstrated a genetic association $(13,14)$.

This review will focus on MVP due to myxomatous valvular degeneration. In myxomatous valve degeneration, diffuse thickening, redundancy, and elongation of mitral valve leaflets occur in association with an abnormality of the chordae. Barlow's disease and fibroelastic deficiency (FED) are ends of the myxomatous MVP spectrum. Barlow's disease is often found in middleaged patients with severe annular dilatation, excessive valvular tissue, thickened or thin chordae, and prolapse of most of the mitral leaflet segments (15). On the other hand, FED is more often 
found in elderly patients with less severe dilatation of the mitral annulus and thickening of valve tissue predominantly within the prolapse segments with thinner non-prolapse segments and chordae (15).

In addition to diagnosing MVP and quantifying associated mitral regurgitation, cardiac imaging is emerging as a tool to risk stratify for malignant VA and SCD. In this review, we briefly discuss recent studies which have identified cardiac imagingbased risk markers of these adverse events in patients with MVP.

\section{INCIDENCE OF MALIGNANT VENTRICULAR ARRHYTHMIA AND SUDDEN CARDIAC DEATH}

There are two broad sets of data on MVP and SCD in the literature: one is from autopsy studies of subjects with SCD and the other is from observational studies on the incidence of SCD among living patients with MVP. The cause of SCD in MVP patients is assumed to be malignant VA $(16,17)$. In fact, a recent study identified a strong association between VA burden and increasing mortality risk among patients with MVP (18). Notably, data on the true incidence of MVP in SCD patients from autopsy studies is underestimated (19). Many studies despite the confirmed presence of MVP in SCD patients categorized them as "undetermined" (19). A meta-analysis found a significant heterogeneity among autopsy studies investigating the cause of SCD (3). They reported that MVP was present in $11.7 \%$ of SCD patients without other structural heart disease (3). Basso et al. reported MVP to be the third most common finding in SCD autopsy cases of young subjects ( $<40$ years) with a prevalence of $12 \%$ (20). Another study from France reviewed negative medicolegal autopsies of 1,000 adults ( $<65$ years) for cardiac causes and found 125 subjects had MVP (21). All these suggest MVP to be highly prevalent among SCD cases.

Among living patients with MVP, there is wide variability in the limited data reported on the incidence of SCD in MVP. A meta-analysis reported the incidence of SCD to be $0.14 \%$ from two observational studies comprising 520 patients (3). Most likely, this is underreported due to lack of studies where data have been collected systematically. A recent large prospective study $(N=177)$, where MVP was diagnosed by cardiac magnetic resonance $(\mathrm{CMR})$, reported $1.2 \%$ annual event rate of SCD or malignant VA (2). The reported incidence of premature ventricular extrasystole (PVC) or ventricular tachycardia is very high on 24-h ambulatory Holter monitoring among patients with MVP with a recent study of consecutive patients $(n=595)$ with MVP and 24-h ambulatory Holter monitoring finding nearly $43 \%$ having either PVC burden $>5 \%$ or ventricular tachycardia (18).

\section{RISK STRATIFICATION USING CLINICAL VARIABLES}

Demographically, MVP patients who suffer from SCD are described to be younger and more often females $(1,17,22)$. T-wave inversion/ST-segment depression and QTc prolongation are often described in living patients with $\operatorname{MVP}(1,18,23,24)$.
Furthermore, a recent large series $(n=595)$ found the presence of T-wave inversion/ST-segment depression to be associated with a nearly 2-fold increased risk of mild-moderate VA and 8-fold increased risk of severe VA (18). Basso et al. found T-wave inversion in the inferior leads of antemortem electrocardiogram in 10 out 12 patients with MVP who suffered from SCD (1).

\section{APPLICATION OF CARDIAC IMAGING FOR RISK ASSESSMENT}

The diagnosis of MVP is fundamentally made by cardiac imaging-primarily echocardiography. In addition to establishing the diagnosis of MVP, echocardiography can be used to quantify associated mitral regurgitation and left ventricular (LV) remodeling. Recently, CMR has gained traction for the assessment of valvular heart disease. It can provide more accurate quantification of regurgitation volume and LV remodeling (25). This is in part due to its ability to compute LV volumes without the need for geometric assumptions. Taking this into notice, the recent American Society of Echocardiography recommends referral for CMR for quantification of mitral regurgitation in scenarios when there are discordances in the various echocardiographic parameters (26). For diagnosing MVP, the same criteria of $2 \mathrm{~mm}$ leaflet displacement in a three-chamber long-axis view can be applied to CMR (27). CMR can also identify the prolapsed scallops within each leaflet using a stack of cine images (Figure 1) (27). Further, CMR is ideally suited for risk stratification of VA in patients with MVP due to its unique ability to non-invasively identify focal myocardial fibrosis.

\section{Valve Morphology}

The presence of bileaflet prolapse on echocardiography with redundant valve leaflets is one of the major markers of increased incidence of VA and SCD among patients with MVP. It is reported that nearly $70 \%$ of cases with MVP and SCD had bileaflet prolapse, while only $26 \%$ had posterior leaflet prolapse (17). A similarly high prevalence of bileaflet prolapse (70\%) among autopsy cases of MVP was noted (1). Redundancy of mitral valve leaflets, a typical characteristic of myxomatous mitral valve prolapse, is also described in autopsy cases of SCD with MVP. A meta-analysis reported that 72 out of 73 confirmed SCD cases with MVP had redundant leaflets (17).

\section{Myocardial Fibrosis}

Autopsy studies have demonstrated the presence of myocardial fibrosis among patients with $\operatorname{MVP}(22,28)$. However, due to small sample size and lack of systematic analysis, knowledge gaps remain. By contrast, CMR allows non-invasive assessment of focal replacement fibrosis in the LV by utilizing late gadolinium enhancement (LGE). Using CMR, several studies have reported the presence of LV myocardial fibrosis among patients with MVP $(1,2,27,29)$. These studies show that fibrosis often occurs in the posteromedial papillary muscle and adjacent LV wall segment (e.g., inferior and inferolateral LV walls). Besides being focal, LGE fibrosis is typically of mid-myocardial or patchy pattern 

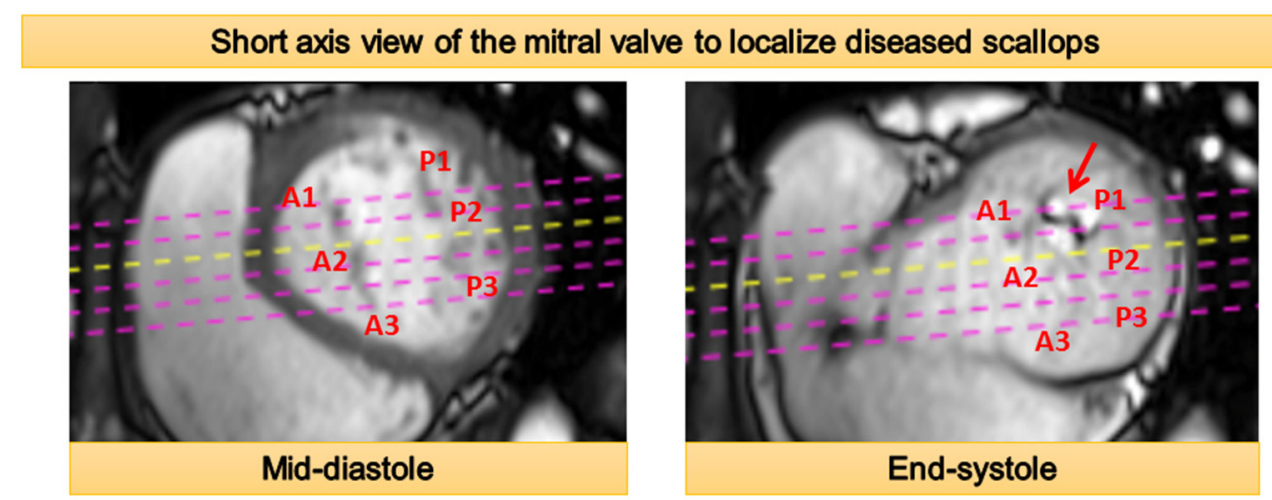

$4 \mathrm{~mm}$ high resolution long axis views of the mitral valve scallops
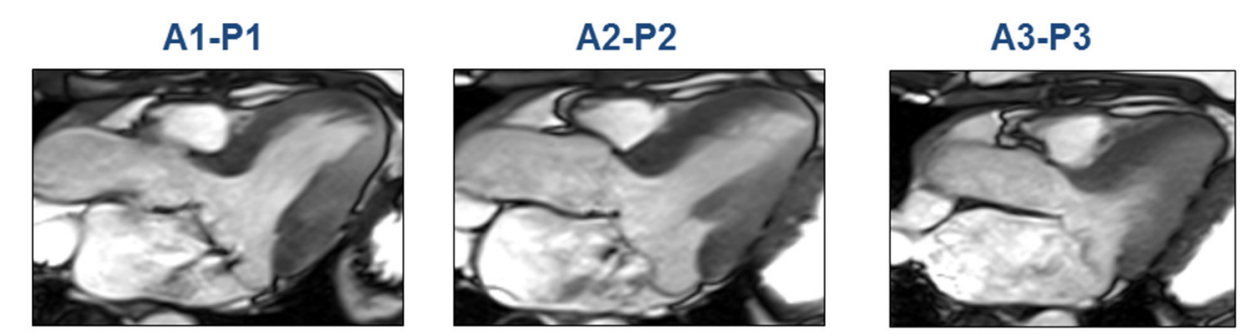

FIGURE 1 | Cardiac magnetic resonance approach to assessment of mitral valve morphology and mechanism of mitral regurgitation. A stack of high-resolution three-chamber cine views perpendicular to the short axis of the valve are acquired to investigate individual mitral valve scallops as demonstrated in the artwork.

in patients with MVP (Figure 2) (2). This focal distribution of fibrosis is unique to patients with MVP and cannot be ascribed to $\mathrm{LV}$ remodeling due to mitral regurgitation (2). One of the proposed mechanism of this regional fibrosis is repeated systolic papillary muscle traction $(30,31)$. A paradoxical movement of papillary muscle tip during systole is described; while the LV annulus moves toward the apex, the papillary muscle tip moves in the opposite direction toward the LA (31). It is hypothesized that excessive and repeated papillary muscle traction by the prolapsing leaflets leads to the development of LV fibrosis (32). However, it is difficult to rule out whether these patients have a distinct underlying cardiomyopathy causing regional fibrosis.

Several studies provide antecedent association to the presence of this regional myocardial fibrosis to complex VA $(2,27,33)$ (Table 1). Han et al. demonstrated that 8/10 MVP patients with complex VA had myocardial fibrosis in the region of papillary muscle (27). In another study, Kitkungvan et al. prospectively followed a large series of MVP patients $(n=177)$ over a median period of 3.7 years. In his cohort, eight patients had either ventricular tachycardia (VT) or aborted SCD (2). Of these, five patients had mid-wall or patchy myocardial fibrosis (nonischemic pattern) in the inferobasal region of the LV.

It is well-documented in the literature that the presence of scar can lead to the genesis of ventricular arrhythmia. Some viable tissue embedded in dense scar can form slow conduction channels which can generate a re-entry circuit causing arrhythmias (34). However, further evidence is needed to substantiate that this regional fibrosis reported among patients with MVP is the precipitating cause of ventricular arrhythmia. These patients may have some underlying electrical abnormalities like QTc prolongation which is causing the VA. Therefore, further evidence is provided by electrophysiological studies to validate this hypothesis. ECG, the most commonly available electrophysiological tool, has demonstrated that VA are of right bundle branch block morphology among patients with MVP indicating that arrhythmias originate in the LV (1). Moreover, in a study where ablation was attempted among MVP patients who survived cardiac arrest or have symptomatic ventricular extrasystoles, the papillary muscle or subvalvular mitral apparatus region was the primary focus for ventricular fibrillation or dominant ventricular extrasystole (35). An earlier study using vectorcardiography of surface electrocardiogram reported that the origin of ventricular extrasystole in patients with MVP is in the posterobasal region of the LV (36). These concordances of the trigger site for arrhythmias and the presence of myocardial fibrosis in the same region are unlikely to be mere coincidence. One hypothesis for the genesis of arrhythmias in these patients is that morphological changes around the mitral annular plane and papillary muscle, combined with excessive motion due to mitral prolapse in this region, cause electrical instability leading to VA $(37,38)$.

More corroborating evidence is provided by autopsy studies. Basso et al. systematically investigated all young adults $(<40$ years $)$ with SCD $(n=650)$ in the Veneto region in Italy between 


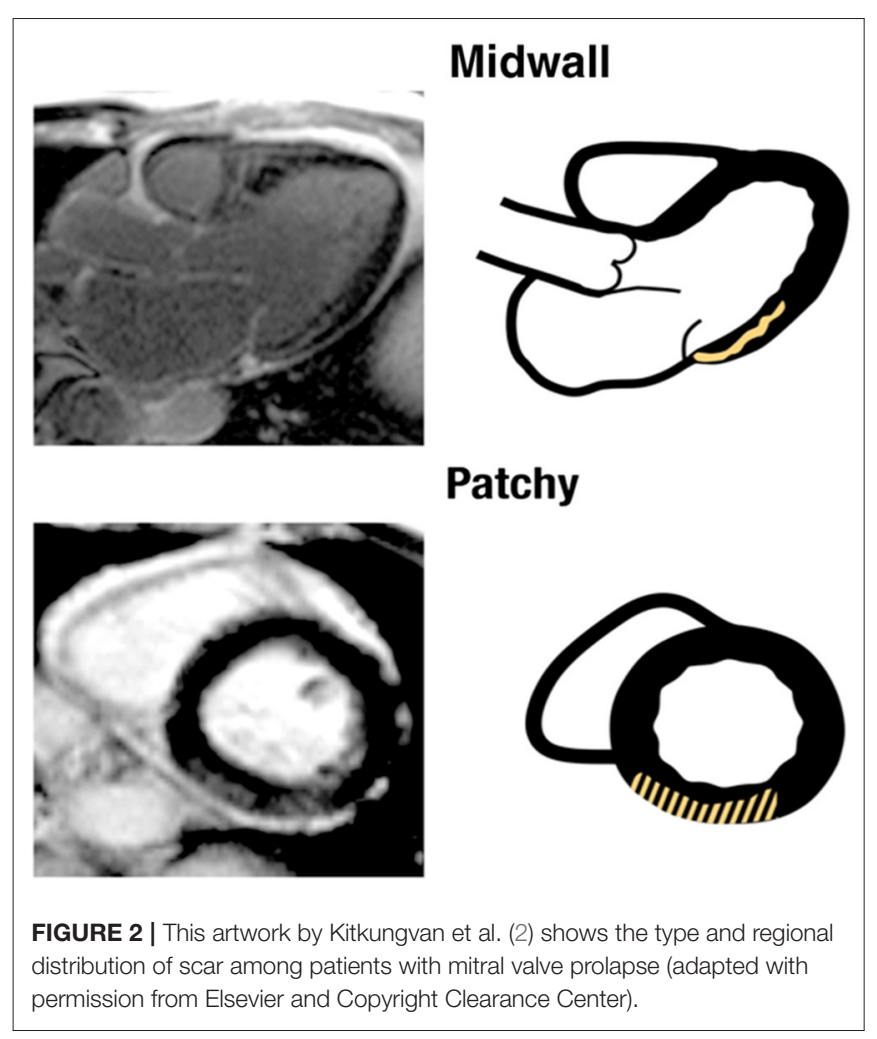

1982 and 2013 (1). They identified 43 patients with MVP. All 43 of these patients had patchy fibrosis in the region of the posterior papillary muscle and the LV wall adjacent to it. They further investigated 30 living patients with MVP with evidence of complex VA and found 28 (93\%) of these patients had myocardial fibrosis in the region of papillary muscle with or without involvement of the inferobasal region of the LV wall.

Considering these findings, the prior theory of an occult MVP cardiomyopathy has evolved into that of a localized mechanical injury of the myocardium such that MVP patients have unique focal fibrosis which is the substrate of SCD and complex VA (38). Further evidence against an occult cardiomyopathy was provided by a recent investigation from our group which noted that accounting for the volume load from the prolapse volume (e.g., the volume of blood above the left ventricular muscle but below the prolapsing mitral leaflets in the ventricularized portion of the left atrium) reconciles the disproportionate LV enlargement that is noted in some MVP patients (39). However, further study is needed, and this is still an area of active investigation.

Cardiac imaging, specifically CMR, may help in risk stratification by assessing fibrosis. In fact, a study demonstrated diffuse LV fibrosis determined by T1 mapping using CMR is also associated with increased risk of complex VA among patients with MVP (33). In this study, the authors found a significant shorter post-contrast T1 time among patients with MVP and complex VA in comparison with those without VA. However, further studies are required to understand if this reduced T1 time is a preceding marker of future LV fibrosis or represents some underlying cardiomyopathy which makes the patients susceptible to VA.

\section{Mitral Annular Disjunction}

Mitral annular disjunction (MAD) is a separation of the posterior mitral annular hinge point from the LV wall while the attachment to the atrium and mitral valve is preserved (Figure 3). The detachment or disjunction allows the excessive motion of the mitral valve during systole. It was first described by Bharati et al. in 1981 in a case report. They reported that the annulus was elongated in patients with MVP and the valve was anchored to the atrial side creating a separation between the atrium and LV (40). Subsequently, Hutchinson et al. performed an autopsy study of the hearts of patients with SCD $(n=900)$ (41). They described that $23(92 \%)$ out of 25 hearts with MVP and SCD had MAD, whereas only $6 \%$ of the hearts with other causes of SCD had this displacement. However, a contradictory report challenging this concept of MAD in patients with MVP was published soon after (42). Angelini et al. studied 13 hearts obtained from necropsy (seven normal and six with MVP). They concluded that there is variation in the atrioventricular junction in all the hearts. They proposed that the appearance of separation is in fact produced by thickening of the valve leaflet at the hinge point and not actual displacement (42).

Recent studies have reported MAD among patients with MVP using echocardiography (two-dimensional and threedimensional) and CMR (43-47) (Table 1). A systematic review of these studies showed that nearly $40-60 \%$ of patients with MVP have MAD (48). Studies have described a mean MAD varying from 5 to $10 \mathrm{~mm}$ in the long-axis view (parasternal or apical) using different imaging modalities (43-45, 47). In fact, a recent study postulated MAD as an independent entity which results in increased risk of VA (46). In this study, of 116 patients, 115 had MAD by echocardiography and 1 by lone CMR. The authors reported that nearly 1 out of 4 patients with MAD did not have concomitant MVP, suggesting that MAD is not necessarily exclusive to patients with MVP. MAD can be observed at different locations on the mitral annulus. However, they observed that MAD is associated with increased risk of VA when it is present at the posterior wall (46). More recently, a new approach to measure MAD using cardiac computed tomography (CCT) is described. In this study, the authors retrospectively studied patients with MVP $(n=90)$ for the presence of MAD (49). They noted MAD detectable by CCT in $\sim 20 \%$ of the patients with severe mitral regurgitation scheduled for mitral valve surgery. This proof-of-concept study highlights a potential role of CCT due to its high spatial resolution, albeit modest temporal resolution.

Further study and understanding of the concept of MAD are warranted. There is a need to further characterize changes in MAD between systole and diastole. Mechanistic data is required as to why MAD may cause an increased risk of VT. Moreover, the impact of surgical mitral valve repair on MAD is unknown and warrants further investigation.

\section{Mechanical Dispersion and Longitudinal Strain}

Mechanical dyssynchrony is associated with VA in patients with cardiomyopathies (50, 51). In an experimental model, it is elucidated that mechanical dyssynchrony is associated with the expression of certain proteins which makes the heart 
TABLE 1 | Studies describing imaging risk factors in patients with MVP.

\begin{tabular}{lll}
\hline Studies $\quad$ Study design $\quad$ Total patients & $\begin{array}{l}\text { Imaging } \\
\text { modality }\end{array}$ & Arrhythmias
\end{tabular}

\section{Myocardial fibrosis}

Han et al. (27)

Basso et al. (1)

44

Bui et al. (33)

Retrospective

41

CMR

Kitkungvan et al. (2)

Prospective

177

CMR

Mitral annular disjunction (MAD)

\begin{tabular}{|c|c|c|c|c|}
\hline Eriksson et al. (43) & Not specified & 32 & TEE & No VA data \\
\hline Carmo et al. (47) & Retrospective & 38 & TTE & $\begin{array}{l}\text { NSVT by Holter (number not } \\
\text { specified) }\end{array}$ \\
\hline Lee et al. (45) & Prospective & 101 & TEE & No VA data \\
\hline Dejgaard et al. (46) & Cross-sectional & $\begin{array}{l}116 \text { patients with } \\
\text { MAD, of which } 90 \\
\text { had MVP }\end{array}$ & $\begin{array}{l}115 \text { had TTE } \\
\text { and } 83 \\
\text { patients had } \\
\text { CMR }\end{array}$ & $\begin{array}{l}26 \text { had NSVT and } 14 \text { had sustained } \\
\text { VT or SCD }\end{array}$ \\
\hline Essayagh et al. (44) & Prospective & 89 & CMR & NSVT, number not specified \\
\hline
\end{tabular}

Mechanical dispersion

Ermakov et al. (54)

Retrospective

59

TTE

32 patients had complex VA; among these, 9 had secondary prevention ICD

10 patients had either VT or VF
8 patients (NSVT or couplets)
30 patients (VF $=2, \mathrm{VT}=1, \mathrm{NSVT}=$
27 )

14 patients had NSVT (out of 32 with Holter data)

8 patients had inducible $\mathrm{VT}$, sustained $\mathrm{VT}$, or sudden cardiac death over 3.7 years follow-up.
10 had PM fibrosis. All 8 with VA had fibrosis

30 patients with LGE at least one region (25 PM, 16 inferolateral mid-wall, 24 inferolateral basal wall). 28 out 30 with VA had fibrosis

11 patients had PM fibrosis; 5 out of 14 patients with VA had PM fibrosis

65 patients had myocardial fibrosis. The most common locations were basal or mid inferolateral wall and basal inferior wall. Arrhythmic event rate of $7.7 \%$ in MVP patients with replacement fibrosis vs. $2.7 \%$ in MVP patients without replacement fibrosis

31 of 32 patients had MAD with mean MAD of $10 \pm 3 \mathrm{~mm}$

21 patients had MAD. Average MAD was $7.4 \pm 8.7 \mathrm{~mm}$. Patients with NSVT had larger mean MAD. MAD $\geq 8.5 \mathrm{~mm}$ was associated with NSVT

42 patients had MAD with a median MAD of $8.9 \mathrm{~mm}$

64 patients with MVP had MAD

31 patients had MAD with a mean MAD of $8 \pm 4 \mathrm{~mm}$. Patients with MAD had more often NSVT

Patients with MVP and VA had higher mechanical dispersion in comparison to those with MVP and no VA (mean $59 \pm 21$ vs. $43 \pm 12, P<0.001)$

12 (57\%) patients had Pickelhaube sign with late high-velocity systolic spike ( $\geq 16 \mathrm{~cm} / \mathrm{s}$ ) with higher incidence of malignant VA (67 vs. $22 \%)$

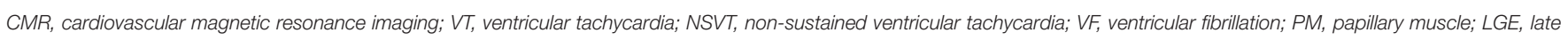
gadolinium enhancement; VA, ventricular arrhythmia; TTE, transthoracic echocardiography, TEE, transesophageal echocardiography; MVP, mitral valve prolapse.

susceptible to complex VA (52). Mechanical dyssynchrony can be quantified with multiple techniques, including deformation imaging and tissue Doppler imaging (53). Mechanical dispersion is one of the methods to quantify mechanical dyssynchrony. It is derived using the standard deviation of time-to-peak of shortening of $18 \mathrm{LV}$ segments using deformation imaging in the 3 apical views. A recent study investigated the presence of mechanical dyssynchrony among patients with MVP and found that patients with MVP and VA had significantly higher mechanical dispersion compared with those with MVP and no
VA (54). This increased dispersion can be related to myocardial fibrosis observed in MVP patients. Regional fibrosis causes delayed contraction in segments with fibrosis leading to increased mechanical dispersion. This could be another less costly but effective approach to identify MVP patients at high risk of SCD and VA using echocardiography.

Besides mechanical dispersion, the magnitude of longitudinal strain can be used to identify early signs of subclinical cardiomyopathy among patients with MVP. One study described decreased longitudinal LV strain in patients with classical MVP 


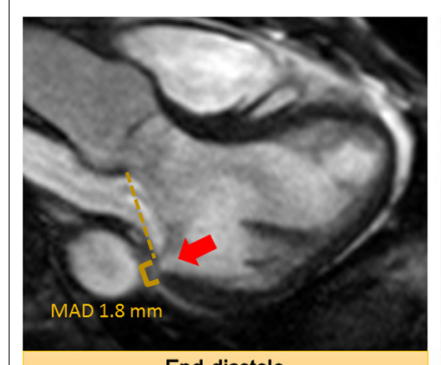

End-diastole

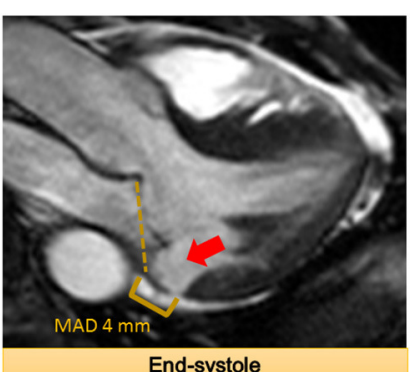

FIGURE 3 | The mitral annular disjunction (MAD) at the inferolateral wall denoted by the arrow is demonstrated. It should be noted that MAD increases from end-diastole to end-systole.
(>5 mm leaflet thickness) (55). Another study demonstrated that basal LV segments have higher longitudinal strain in patients with Barlow's disease indicating hypermobility, but overall, this study did not find any difference in global LV function between patients with Barlow's disease and FED (56). More recently, a study showed that regional postsystolic shortening is observed more often among MVP patients with malignant VA (57). However, this study comprises only 44 patients with just five of them having malignant VA. Therefore, the findings need to be corroborated in larger settings.

\section{Pickelhaube Sign}

Muthukumar et al. using pulsed-wave Doppler measured mitral annular velocity in a series of 21 patients with MVP (58). They noted a distinctive spike mid-systole to late-systole at the lateral mitral annulus $(>16 \mathrm{~cm} / \mathrm{s})$ in 12 of 21 patients (Figure 4) (58). Of these 12 patients, eight patients suffered from malignant VA at follow-up. No similar spike of increased velocity was observed at the medial mitral annulus. The authors hypothesized that the tugging of the posteromedial papillary muscle of the prolapsing myxomatous mitral leaflet causes the basal LV wall to pull toward the apex with increased velocity. Pickelhaube is the term used to describe the German military helmet which has a spike on top; therefore, this was used to describe the distinctive spike. Later, the same group showed that the Pickelhaube sign in patients with MVP is found with higher frequency at the posterolateral annulus in the apical long-axis view (59). This is a novel and relatively simple approach. Larger studies are required to validate the findings.

\section{RISK STRATIFICATION}

MVP is widely prevalent in the community. Although the risk of SCD may be low, it is of serious concern due to its devastating consequences. A risk stratification strategy is needed to identify patients at high risk of this consequential complication. Figure 5 summarizes the factors associated with SCD along with the likely mechanism. Among the clinical variables which suggest increased risk are as follows: female sex,

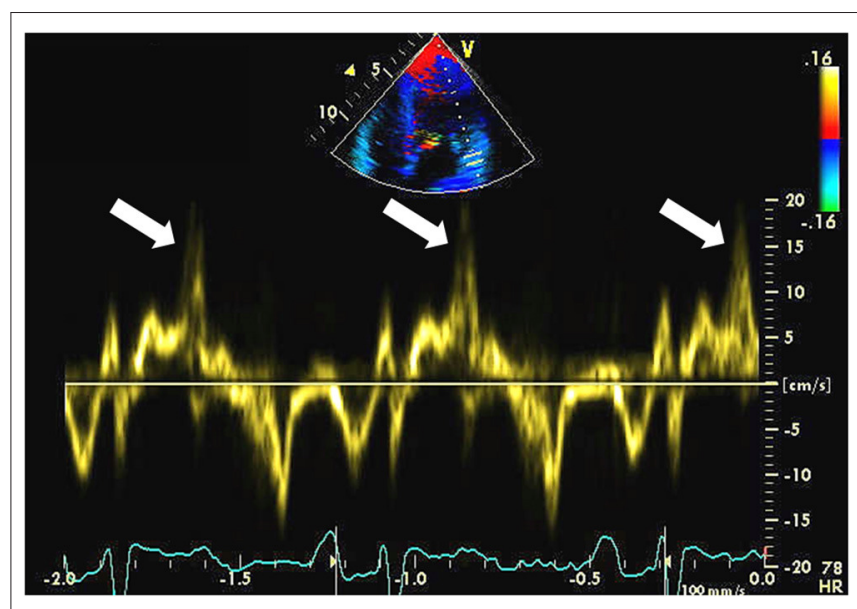

FIGURE 4 | An echocardiographic example of the "Pickelhaube sign" which reflects increased velocity at the lateral mitral annulus in mid-systole to late-systole. The velocity spike is denoted by a white arrow.

bileaflet prolapse, and ECG changes (ST and T-wave changes in the inferior leads) $(17,38)$. Besides these, other risk factors can be clinical history of palpitations or unexplained syncope. A 24-h Holter monitoring may be considered to estimate the burden of VA. If any of this is present, a CMR can be performed for the assessment of LV fibrosis, especially in the posterior subpapillary region. As explained before, most likely, this LV fibrosis serves as the substrate for the VA. Slow conduction channels embedded in this fibrotic region along with hypermobility of the basal segments and a PVC are possible triggers leading to a full-fledged malignant VA. The presence of a concomitant underlying cardiomyopathy and MAD are other hypothetical factors which may lead to increased risk of SCD and VA.

\section{FUTURE DIRECTIONS}

There are many small series demonstrating SCD and malignant VA among patients with $\operatorname{MVP}(1,2)$. However, there is a need for a large multicenter study where patients are enrolled prospectively and systematically followed at regular intervals with Holter monitoring and periodic follow-up with multimodality imaging-particularly echocardiography and CMR. This will provide insights into the true risk of SCD and malignant VA among patients with MVP. Imaging may aid by providing high-risk markers which may identify patients who warrant closer follow-up. Moreover, imaging findings along with clinical and genetics/molecular research can be combined to develop a scoring system which can eventually be applied to identify patients at high risk of SCD and considered for implantable cardioverter defibrillator device as primary prevention. The most recent ACC/AHA/HRS guidelines from 2017 note the increased risk of VA among patients with MVP and a potential association with SCD, but there are no specific recommendations made for therapeutic intervention (60). Among the imaging risk markers, factors which should 


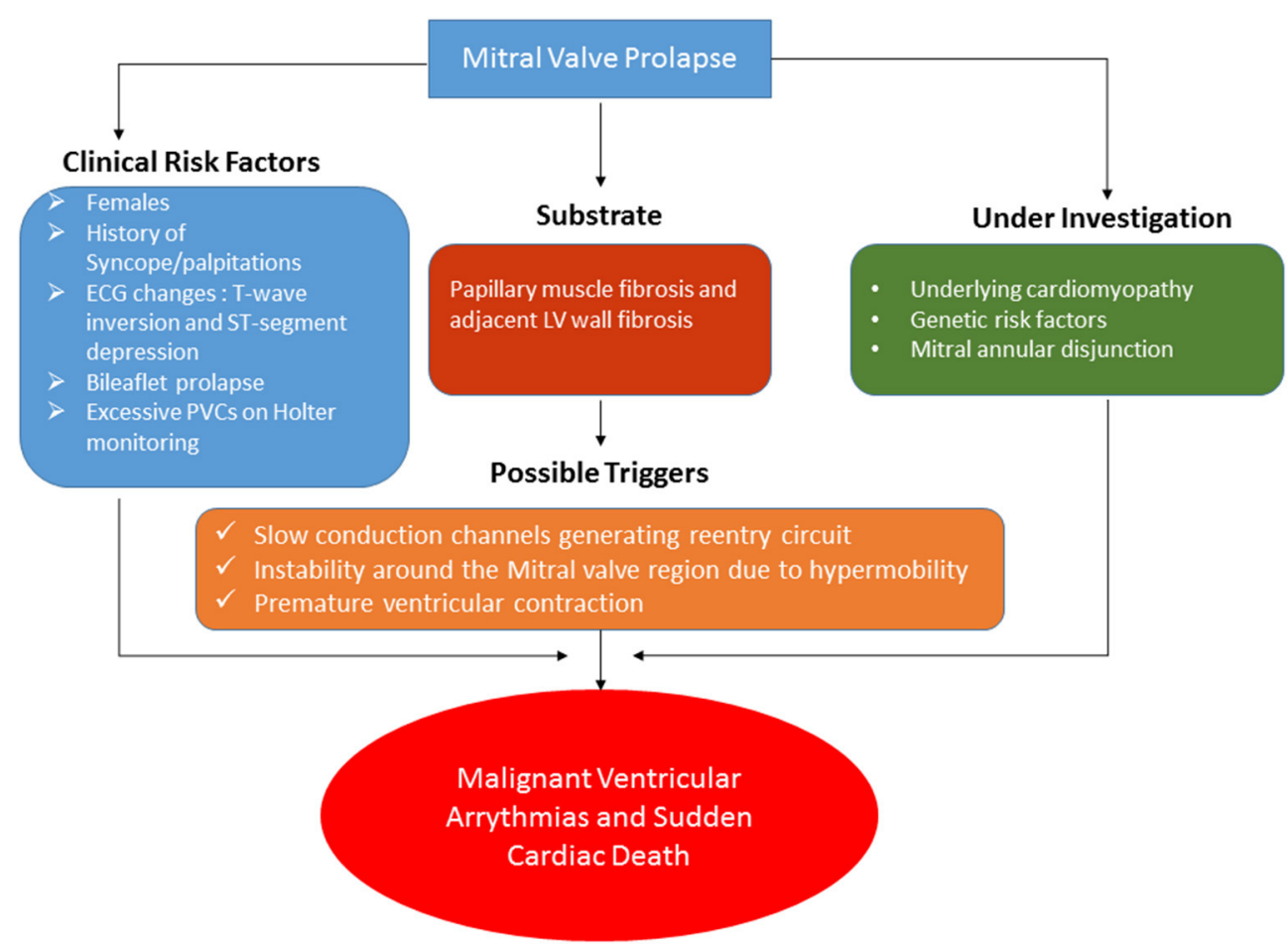

FIGURE 5 | The clinical risk factors, mechanism, and hypothetical factors still under investigation related to the potential increased risk of malignant ventricular arrhythmias and sudden cardiac death among patients with MVP are illustrated.

be investigated are the role of $\mathrm{LV}$ fibrosis in the posterior subpapillary region, MAD, T1 mapping, longitudinal strain, and Pickelhaube signs. The role of other imaging modalities, such as positron emission tomography (PET) should also be considered. A recent study using PET demonstrated an increase uptake of FDG with concurrent LGE by CMR in patients with MVP, raising the possibility of an inflammatory or ischemic component in these segments among asymptomatic patients with MVP (61). Further studies will provide more insight into the role of PET in risk stratification of MVP patients.

\section{CONCLUSIONS}

MVP is a widely prevalent disease and studies have shown the increased risk of SCD and complex VA in these patients. Several imaging markers are shown to be related to this arrhythmic risk. Aside from its role as a cornerstone for identifying MVP, echocardiography can serve as a gatekeeper for further investigations if bileaflet prolapse or signs of any cardiomyopathy are noted. The strength of CMR is its ability to perform tissue characterization to identify focal myocardial fibrosis in the posterior papillary muscle and adjacent LV wall. The presence of fibrosis has one of the most compelling mechanistic basis and supporting evidence in the literature. Patients presenting with syncope, pre-syncope, palpitations, or evidence of VA should be investigated with CMR for further risk stratification.

\section{AUTHOR CONTRIBUTIONS}

All authors listed have made a substantial, direct and intellectual contribution to the work, and approved it for publication.

\section{FUNDING}

BT received grant from Augustinus Fond and Regionnordjylland Forskningsfond. DS received salary support from the National Science Foundation (grants CNS-1646566 and CNS-1931884) and the National Institutes of Health (1R01HL137763-01), and FD was funded through R03 HL14523 and R01HL153447.

\section{REFERENCES}

1. Basso C, Perazzolo Marra M, Rizzo S, De Lazzari M, Giorgi B, Cipriani A, et al. Arrhythmic mitral valve prolapse and sudden cardiac death. Circulation. (2015) 132:556-66. doi: 10.1161/CIRCULATIONAHA.115. 016291

2. Kitkungvan D, Nabi F, Kim RJ, Bonow RO, Khan MA, Xu J, et al. Myocardial fibrosis in patients with primary mitral regurgitation with and without prolapse. J Am Coll Cardiol. (2018) 72:823-34. doi: 10.1016/j.jacc.2018.06.048

3. Nalliah CJ, Mahajan R, Elliott AD, Haqqani H, Lau DH, Vohra JK, et al. Mitral valve prolapse and sudden cardiac death: a systematic review and meta-analysis. Heart. (2019) 105:144-51. doi: 10.1136/heartjnl-2017-312932 
4. Nishimura RA, McGoon MD, Shub C, Miller FA Jr., Ilstrup DM, Tajik AJ. Echocardiographically documented mitral-valve prolapse. Longterm follow-up of 237 patients. N Engl J Med. (1985) 313:1305-9. doi: 10.1056/NEJM198511213132101

5. Barlow JB, Pocock WA. The significance of late systolic murmurs and mid-late systolic clicks. MD State Med J. (1963) 12:76-7.

6. Criley JM, Lewis KB, Humphries JO, Ross RS. Prolapse of the mitral valve: clinical and cine-angiocardiographic findings. Br Heart J. (1966) 28:488-96. doi: $10.1136 /$ hrt.28.4.488

7. Levine RA, Stathogiannis E, Newell JB, Harrigan P, Weyman AE. Reconsideration of echocardiographic standards for mitral valve prolapse: lack of association between leaflet displacement isolated to the apical four chamber view and independent echocardiographic evidence of abnormality. J Am Coll Cardiol. (1988) 11:1010-9. doi: 10.1016/S0735-1097(98)90059-6

8. Devereux RB, Jones EC, Roman MJ, Howard BV, Fabsitz RR, Liu JE, et al. Prevalence and correlates of mitral valve prolapse in a population-based sample of American Indians: the Strong Heart Study. Am J Med. (2001) 111:679-85. doi: 10.1016/S0002-9343(01)00981-0

9. Freed LA, Levy D, Levine RA, Larson MG, Evans JC, Fuller DL, et al. Prevalence and clinical outcome of mitral-valve prolapse. NEngl J Med. (1999) 341:1-7. doi: 10.1056/NEJM199907013410101

10. Savage DD, Garrison RJ, Devereux RB, Castelli WP, Anderson SJ, Levy D, et al. Mitral valve prolapse in the general population. 1. Epidemiologic features: the Framingham Study. Am Heart J. (1983) 106:5716. doi: 10.1016/0002-8703(83)90704-4

11. Warth DC, King ME, Cohen JM, Tesoriero VL, Marcus E, Weyman AE. Prevalence of mitral valve prolapse in normal children. J Am Coll Cardiol. (1985) 5:1173-7. doi: 10.1016/S0735-1097(85)80021-8

12. Levine RA, Handschumacher MD, Sanfilippo AJ, Hagege AA, Harrigan P, Marshall JE, et al. Three-dimensional echocardiographic reconstruction of the mitral valve, with implications for the diagnosis of mitral valve prolapse. Circulation. (1989) 80:589-98. doi: 10.1161/01.CIR.80.3.589

13. Delling FN, Rong J, Larson MG, Lehman B, Osypiuk E, Stantchev P, et al. Familial clustering of mitral valve prolapse in the community. Circulation. (2015) 131:263-8. doi: 10.1161/CIRCULATIONAHA.114.0 12594

14. Delling FN, Li X, Li S, Yang Q, Xanthakis V, Martinsson A, et al. Heritability of mitral regurgitation: observations from the Framingham Heart Study and Swedish Population. Circ Cardiovasc Genet. (2017) 10:e001736. doi: 10.1161/CIRCGENETICS.117.001736

15. Fornes P, Heudes D, Fuzellier JF, Tixier D, Bruneval P, Carpentier A. Correlation between clinical and histologic patterns of degenerative mitral valve insufficiency: a histomorphometric study of 130 excised segments. Cardiovasc Pathol. (1999) 8:81-92. doi: 10.1016/S1054-8807(98)00021-0

16. Sriram CS, Syed FF, Ferguson ME, Johnson JN, Enriquez-Sarano M, Cetta F, et al. Malignant bileaflet mitral valve prolapse syndrome in patients with otherwise idiopathic out-of-hospital cardiac arrest. J Am Coll Cardiol. (2013) 62:222-30. doi: 10.1016/j.jacc.2013.02.060

17. Han HC, Ha FJ, Teh AW, Calafiore P, Jones EF, Johns J, et al. Mitral valve prolapse and sudden cardiac death: a systematic review. J Am Heart Assoc. (2018) 7:e010584. doi: 10.1161/JAHA.118.010584

18. Essayagh B, Sabbag A, Antoine C, Benfari G, Yang LT, Maalouf J, et al. Presentation and outcome of arrhythmic mitral valve prolapse. J Am Coll Cardiol. (2020) 76:637-49. doi: 10.1016/j.jacc.2020.06.029

19. Miller MA, Dukkipati SR, Turagam M, Liao SL, Adams DH, Reddy VY. Arrhythmic mitral valve prolapse: JACC review topic of the week. J Am Coll Cardiol. (2018) 72:2904-14. doi: 10.1016/j.jacc.2018.09.048

20. Basso C, Calabrese F, Corrado D, Thiene G. Postmortem diagnosis in sudden cardiac death victims: macroscopic, microscopic and molecular findings. Cardiovasc Res. (2001) 50:290-300. doi: 10.1016/S0008-6363(01)00261-9

21. Loire R, Tabib A. Unexpected sudden cardiac death. An evaluation of 1000 autopsies. Arch Mal Coeur Vaiss. (1996) 89:13-8.

22. Dollar AL, Roberts WC. Morphologic comparison of patients with mitral valve prolapse who died suddenly with patients who died from severe valvular dysfunction or other conditions. J Am Coll Cardiol. (1991) 17:921-31. doi: 10.1016/0735-1097(91)90875-A

23. Lerdani H, Moreyra A, Manubens S, Belardi J, Fava M, Sheldon WC. Electrocardiographic findings in 125 patients with idiopathic prolapse of the mitral valve studied by angiography. Cleve Clin Q. (1976) 43:181-94. doi: $10.3949 /$ ccjm.43.3.181

24. Bhutto ZR, Barron JT, Liebson PR, Uretz EF, Parrillo JE. Electrocardiographic abnormalities in mitral valve prolapse. Am J Cardiol. (1992) 70:265-6. doi: 10.1016/0002-9149(92)91287-E

25. Uretsky S, Gillam L, Lang R, Chaudhry FA, Argulian E, Supariwala A, et al. Discordance between echocardiography and MRI in the assessment of mitral regurgitation severity: a prospective multicenter trial. J Am Coll Cardiol. (2015) 65:1078-88. doi: 10.1016/j.jacc.2014.12.047

26. Zoghbi WA, Adams D, Bonow RO, Enriquez-Sarano M, Foster E, Grayburn PA, et al. Recommendations for noninvasive evaluation of native valvular regurgitation: a report from the American Society of Echocardiography Developed in Collaboration with the Society for Cardiovascular Magnetic Resonance. J Am Soc Echocardiogr. (2017) 30:303-71. doi: 10.1016/j.echo.2017.01.007

27. Han Y, Peters DC, Salton CJ, Bzymek D, Nezafat R, Goddu B, et al. Cardiovascular magnetic resonance characterization of mitral valve prolapse. JACC Cardiovasc Imaging. (2008) 1:294-303. doi: 10.1016/j.jcmg.2008.01.013

28. Chesler E, King RA, Edwards JE. The myxomatous mitral valve and sudden death. Circulation. (1983) 67:632-9. doi: 10.1161/01.CIR.67.3.632

29. Pradella S, Grazzini G, Brandani M, Calistri L, Nardi C, Mori F, et al. Cardiac magnetic resonance in patients with mitral valve prolapse: focus on late gadolinium enhancement and T1 mapping. Eur Radiol. (2019) 29:1546-54. doi: 10.1007/s00330-018-5634-5

30. Han Y, Peters DC, Kissinger KV, Goddu B, Yeon SB, Manning WJ, et al. Evaluation of papillary muscle function using cardiovascular magnetic resonance imaging in mitral valve prolapse. Am J Cardiol. (2010) 106:243-8. doi: 10.1016/j.amjcard.2010.02.035

31. Sanfilippo AJ, Harrigan P, Popovic AD, Weyman AE, Levine RA. Papillary muscle traction in mitral valve prolapse: quantitation by twodimensional echocardiography. J Am Coll Cardiol. (1992) 19:564-71. doi: 10.1016/S0735-1097(10)80274-8

32. Perazzolo Marra M, Basso C, De Lazzari M, Rizzo S, Cipriani A, Giorgi B, et al. Morphofunctional abnormalities of mitral annulus and arrhythmic mitral valve prolapse. Circ Cardiovasc Imaging. (2016) 9:e005030. doi: 10.1161/CIRCIMAGING.116.005030

33. Bui AH, Roujol S, Foppa M, Kissinger KV, Goddu B, Hauser TH, et al. Diffuse myocardial fibrosis in patients with mitral valve prolapse and ventricular arrhythmia. Heart. (2017) 103:204-9. doi: 10.1136/heartjnl-2016-309303

34. de Bakker JM, Coronel R, Tasseron S, Wilde AA, Opthof T, Janse MJ, et al. Ventricular tachycardia in the infarcted, Langendorff-perfused human heart: role of the arrangement of surviving cardiac fibers. J Am Coll Cardiol. (1990) 15:1594-607. doi: 10.1016/0735-1097(90)92832-M

35. Syed FF, Ackerman MJ, McLeod CJ, Kapa S, Mulpuru SK, Sriram CS, et al. Sites of successful ventricular fibrillation ablation in bileaflet mitral valve prolapse syndrome. Circ Arrhythm Electrophysiol. (2016) 9:e004005. doi: 10.1161/CIRCEP.116.004005

36. Lichstein E. Site of origin of ventricular premature beats in patients with mitral valve prolapse. Am Heart J. (1980) 100:450-7. doi: 10.1016/0002-8703(80)90656-0

37. Hai JJ, Chahal AA, Friedman PA, Vaidya VR, Syed FF, DeSimone CV, et al. Electrophysiologic characteristics of ventricular arrhythmias arising from the aortic mitral continuity-potential role of the conduction system. J Cardiovasc Electrophysiol. (2015) 26:158-63. doi: 10.1111/jce.12587

38. Basso C, Iliceto S, Thiene G, Perazzolo Marra M. Mitral valve prolapse, ventricular arrhythmias, and sudden death. Circulation. (2019) 140:952-64. doi: 10.1161/CIRCULATIONAHA.118.034075

39. El-Tallawi KC, Kitkungvan D, Xu J, Cristini V, Yang EY, Quinones MA, et al. Resolving the disproportionate left ventricular enlargement in mitral valve prolapse due to Barlow disease: insights from cardiovascular magnetic resonance. JACC Cardiovasc Imaging. (2020). doi: 10.1016/j.jcmg.2020.08.029. [Epub ahead of print].

40. Bharati S, Granston AS, Liebson PR, Loeb HS, Rosen KM, Lev M. The conduction system in mitral valve prolapse syndrome with sudden death. Am Heart J. (1981) 101:667-70. doi: 10.1016/0002-8703(81)90235-0

41. Hutchins GM, Moore GW, Skoog DK. The association of floppy mitral valve with disjunction of the mitral annulus fibrosus. N Engl J Med. (1986) 314:535-40. doi: 10.1056/NEJM198602273140902 
42. Angelini A, Ho SY, Anderson RH, Davies MJ, Becker AE. A histological study of the atrioventricular junction in hearts with normal and prolapsed leaflets of the mitral valve. Br Heart J. (1988) 59:712-6. doi: 10.1136/hrt.59.6.712

43. Eriksson MJ, Bitkover CY, Omran AS, David TE, Ivanov J, Ali MJ, et al. Mitral annular disjunction in advanced myxomatous mitral valve disease: echocardiographic detection and surgical correction. J Am Soc Echocardiogr. (2005) 18:1014-22. doi: 10.1016/j.echo.2005.06.013

44. Essayagh B, Iacuzio L, Civaia F, Avierinos JF, Tribouilloy C, Levy F. Usefulness of 3-tesla cardiac magnetic resonance to detect mitral annular disjunction in patients with mitral valve prolapse. Am J Cardiol. (2019) 124:1725-30. doi: 10.1016/j.amjcard.2019.08.047

45. Lee AP, Jin CN, Fan Y, Wong RHL, Underwood MJ, Wan S. Functional implication of mitral annular disjunction in mitral valve prolapse: a quantitative dynamic 3D echocardiographic study. JACC Cardiovasc Imaging. (2017) 10:1424-33. doi: 10.1016/j.jcmg.2016.11.022

46. Dejgaard LA, Skjolsvik ET, Lie OH, Ribe M, Stokke MK, Hegbom F, et al. The mitral annulus disjunction arrhythmic syndrome. J Am Coll Cardiol. (2018) 72:1600-9. doi: 10.1016/j.jacc.2018.07.070

47. Carmo P, Andrade MJ, Aguiar C, Rodrigues R, Gouveia R, Silva JA. Mitral annular disjunction in myxomatous mitral valve disease: a relevant abnormality recognizable by transthoracic echocardiography. Cardiovasc Ultrasound. (2010) 8:53. doi: 10.1186/1476-7120-8-53

48. Bennett S, Thamman R, Griffiths T, Oxley C, Khan JN, Phan T, et al. Mitral annular disjunction: a systematic review of the literature. Echocardiography. (2019) 36:1549-58. doi: 10.1111/echo.14437

49. Putnam AJ, Kebed K, Mor-Avi V, Rashedi N, Sun D, Patel B, et al. Prevalence of mitral annular disjunction in patients with mitral valve prolapse and severe regurgitation. Int J Cardiovasc Imaging. (2020) 36:1363-70. doi: 10.1007/s10554-020-01818-4

50. Tayal B, Gorcsan J III, Delgado-Montero A, Marek JJ, Haugaa KH, Ryo K, et al. Mechanical dyssynchrony by tissue doppler cross-correlation is associated with risk for complex ventricular arrhythmias after cardiac resynchronization therapy. J Am Soc Echocardiogr. (2015). 28:1474-81. doi: 10.1016/j.echo.2015. 07.021

51. Haugaa KH, Smedsrud MK, Steen T, Kongsgaard E, Loennechen JP, Skjaerpe $\mathrm{T}$, et al. Mechanical dispersion assessed by myocardial strain in patients after myocardial infarction for risk prediction of ventricular arrhythmia. JACC Cardiovasc Imaging. (2010) 3:247-56. doi: 10.1016/j.jcmg.2009.11.012

52. Spragg DD, Leclercq C, Loghmani M, Faris OP, Tunin RS, DiSilvestre D, et al. Regional alterations in protein expression in the dyssynchronous failing heart. Circulation. (2003) 108:929-32. doi: 10.1161/01.CIR.0000088782.9 9568.CA

53. Gorcsan J III, Tayal B. Newer echocardiographic techniques in cardiac resynchronization therapy. Card Electrophysiol Clin. (2015) 7:609-18. doi: 10.1016/j.ccep.2015.08.013
54. Ermakov S, Gulhar R, Lim L, Bibby D, Fang Q, Nah G, et al. Left ventricular mechanical dispersion predicts arrhythmic risk in mitral valve prolapse. Heart. (2019) 105:1063-9. doi: 10.1136/heartjnl-2018-314269

55. Malev E, Reeva S, Vasina L, Timofeev E, Pshepiy A, Korshunova A, et al. Cardiomyopathy in young adults with classic mitral valve prolapse. Cardiol Young. (2014) 24:694-701. doi: 10.1017/S1047951113001042

56. van Wijngaarden SE, Abou R, Hiemstra YL, Ajmone Marsan N, Bax JJ, Delgado V. Regional left ventricular myocardial mechanics in degenerative myxomatous mitral valve disease: a comparison between fibroelastic deficiency and Barlow's disease. JACC Cardiovasc Imaging. (2018) 11:1362-4. doi: 10.1016/j.jcmg.2017.11.012

57. Muthukumar L, Jahangir A, Jan MF, Galazka P, Umland M, Schweitzer $\mathrm{MR}$, et al. Left ventricular global and regional deformation in arrhythmic myxomatous bileaflet mitral valve prolapse syndrome. JACC Cardiovasc Imaging. (2020) 13:1842-4. doi: 10.1016/j.jcmg.2020.02.035

58. Muthukumar L, Rahman F, Jan MF, Shaikh A, Kalvin L, Dhala A, et al. The Pickelhaube sign: novel echocardiographic risk marker for malignant mitral valve prolapse syndrome. JACC Cardiovasc Imaging. (2017) 10:107880. doi: 10.1016/j.jcmg.2016.09.016

59. Ignatowski D, Schweitzer M, Pesek K, Jain R, Muthukumar L, Khandheria $\mathrm{BK}$, et al. Pickelhaube spike, a high-risk marker for bileaflet myxomatous mitral valve prolapse: sonographer's quest for the highest spike. J Am Soc Echocardiogr. (2020). 33:639-40. doi: 10.1016/j.echo.2020.02.004

60. Al-Khatib SM, Stevenson WG, Ackerman MJ, Bryant WJ, Callans DJ, Curtis $\mathrm{AB}$, et al. $2017 \mathrm{AHA} / \mathrm{ACC} / \mathrm{HRS}$ guideline for management of patients with ventricular arrhythmias and the prevention of sudden cardiac death: a report of the American College of Cardiology/American Heart Association Task Force on Clinical Practice Guidelines and the Heart Rhythm Society. J Am Coll Cardiol. (2018) 72:e91-220. doi: 10.1161/CIR.0000000000000549

61. Miller MA, Adams DH, Pandis D, Robson PM, Pawale A, Pyzik $\mathrm{R}$, et al. Hybrid positron emission tomography/magnetic resonance imaging in arrhythmic mitral valve prolapse. JAMA Cardiol. (2020). doi: 10.1001/jamacardio.2020.1555. [Epub ahead of print].

Conflict of Interest: The authors declare that the research was conducted in the absence of any commercial or financial relationships that could be construed as a potential conflict of interest.

Copyright (C) 2021 Tayal, Delling, Malahfji and Shah. This is an open-access article distributed under the terms of the Creative Commons Attribution License (CC BY). The use, distribution or reproduction in other forums is permitted, provided the original author(s) and the copyright owner(s) are credited and that the original publication in this journal is cited, in accordance with accepted academic practice. No use, distribution or reproduction is permitted which does not comply with these terms. 